\title{
The Four Corners of Waste Management Sustainability
}

\author{
Godfrey A Uzochukwu* \\ Department of Interdisciplinary Waste Management Institute, Greensboro, North Carolina, USA
}

*Corresponding author: Godfrey A Uzochukwu, Interdisciplinary Waste Management Institute, Greensboro, North Carolina, USA.

\begin{abstract}
The four coners of sustainability are connected. A push on one corner will affect the other corners. Campus infrastructure, energy, climate and air-water-soil provide basic information of the university's consideration towards green environment. Parking area, campus smart buildings, ground cover, drainage systems for reducing soil erosion and runoff, number of students including online students, number of academic faculty and staff and university budget for sustainability impact waste management. Buildings account for $40 \%$ of the energy and $72 \%$ of the electricity used in the United States. Buildings also account for $16 \%$ of United States water consumption, $40 \%$ of all material flows and produce up to $40 \%$ of waste in landfills depending on the region.
\end{abstract}

\section{Introduction}

The four corners of waste management sustainability which include Infrastructure, Air-Water-Soil, global climate, energy is connected. A push on one corner will affect the other corners. Investment in infrastructure, air-water-soil, global climate, energy and water challenges out-weighs the cost of doing nothing. With this in mind, the Interdisciplinary Waste Management Institute (WMI) of North Carolina Agricultural and Technical State University (NC A\&T) began to raise awareness about environmental concerns for NC A\&T students, faculty, staff and individuals from all walks of life. In so doing, WMI embarked on a national conversation about environmental protection through a series of national symposia and conferences. By working together across divides, WMI faculty and student affiliates are demanding new level of leadership to tackle environmental crises and sustainability before it is too late. Environmental crises such as climate driven seas level rise, ocean acidification, waste management, heat waves, wildfires, disease spread, and massive damage of biodiversity and more affect food, water, air, land, energy securities and inflicting serious economic losses globally. WMI is calling for quicker environmental sustainability actions to contribute knowledge and passion for effective solutions. The four corners of waste management sustainability require converging approaches for environmental solutions (Figure 1).

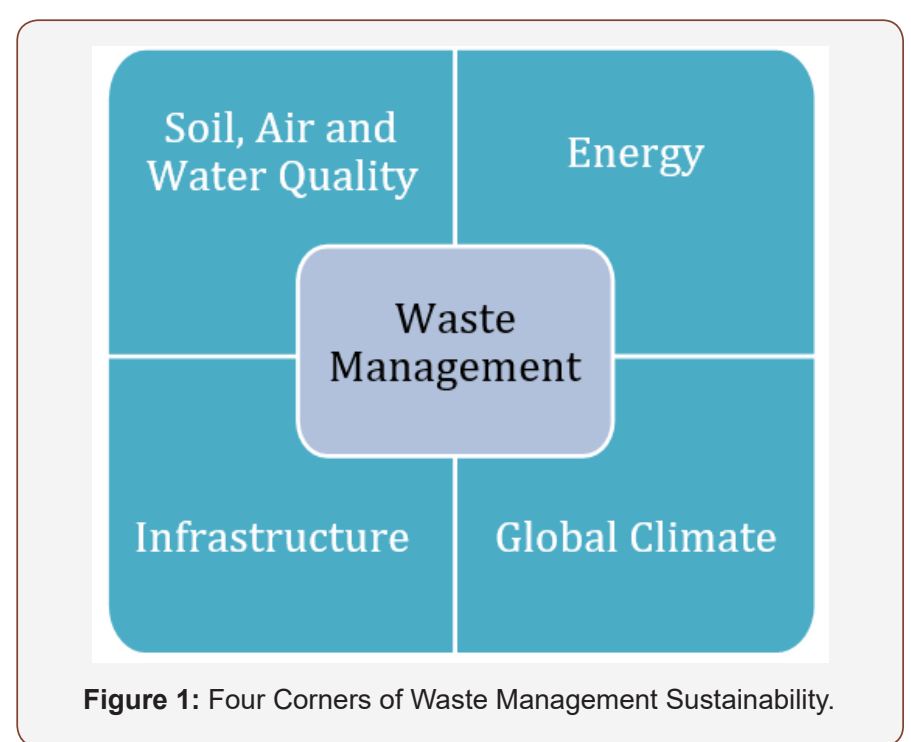

N.C. A\&T has invested in cutting-edge sustainable activities and policies that aim to improve infrastructure, water conservation, energy and climate as well as protect the environment. This is a framework for constructing a green university [1]. Global circumstances demand new solutions for our science and technical fields and an uncompromising campus sustainability expectation among 
students, faculty, staff and administrators. Buildings account for $40 \%$ of the energy and $72 \%$ of the electricity used in the United States. Buildings also account for $16 \%$ of United States water consumption, $40 \%$ of all material flows and produce up to $40 \%$ of waste in landfills depending on the region [2].

\section{Infrastructure}

University infrastructure helps to achieve uncompromising campus sustainability which impact waste management. N.C. A\&T campus is covered with planted grass and tree vegetation yearround for improving air quality, water quality, water absorbance. Drainage systems for reducing soil erosion and runoff are excellent. Total parking area, total main campus smart buildings, number of students, number of online students, number of academic faculty and staff and university budget for sustainability effort impact waste produced. Figure 2 shows students enjoying the campus setting of NC A\&T campus. Infrastructure provides basic information of the university's consideration towards green environment. This indicator shows whether or not N.C. A\&T deserves to be called a green campus (Figure 2).

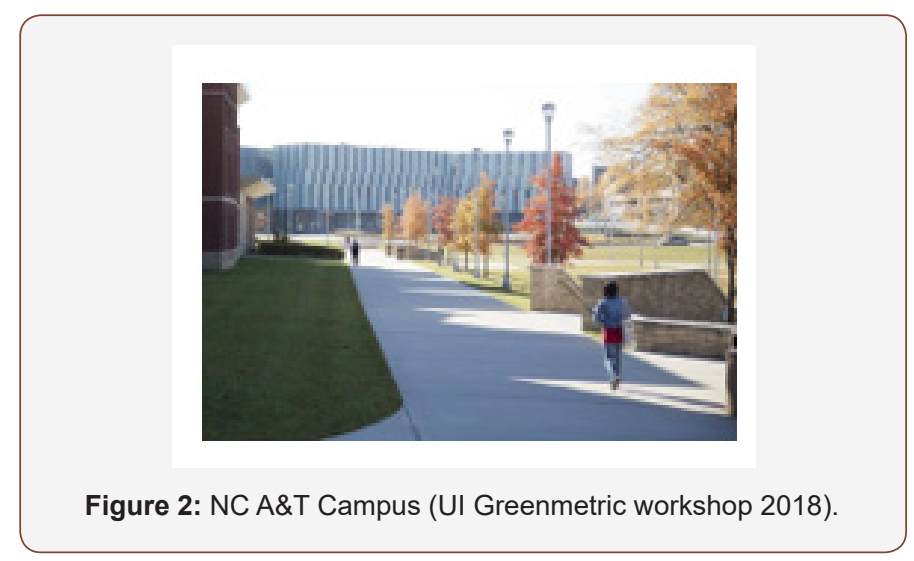

\section{Water}

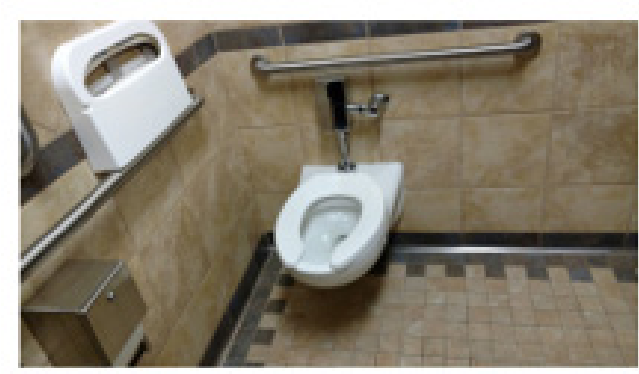

Figure 3: Water efficient toilet. Courtesy: NC A\&T State University.
Water use is an important indicator of Green Campus Figure 3. The goal is to encourage universities to decrease water usage, increase conservation programs, and protect health. Water conservation, water recycling, use of water efficient appliances and treated water consumed impact waste management (Figure 3).

\section{Energy and Climate}

The university's attention to energy and climate change issues is important. NC A\&T is expected to increase its effort in energy efficiency Figure 4 in the campus buildings and to care more about nature and energy produced and consumed (Figure 4).

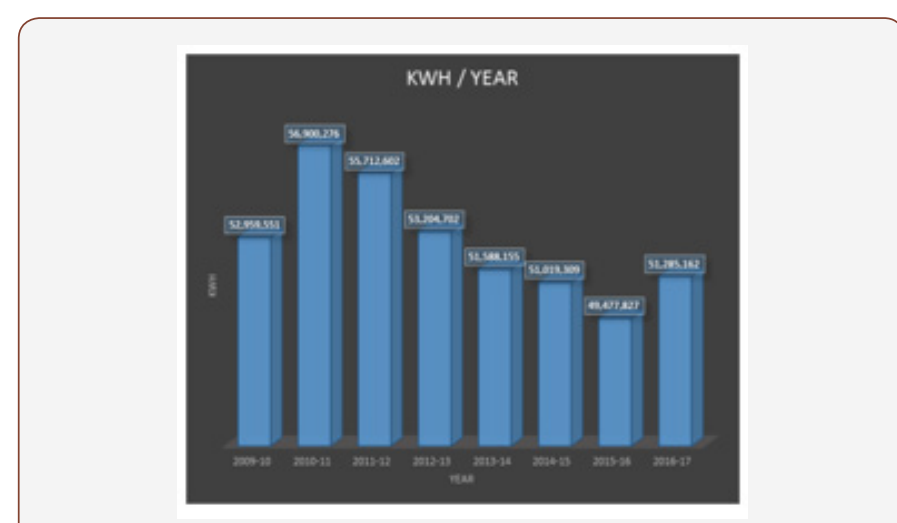

Figure 4: Electricity Usage. Courtesy: NC A\&T State University.

Energy efficient appliances usage, smart building implementation, ratio of electricity usage to campus population, element of green building implementation, greenhouse emission reduction program, energy audits, energy monitoring, lighting upgrades, retro-commissioning process for buildings impact waste management and reduction of greenhouse gas pollutants on campus .

\section{Acknowledgement}

None.

\section{Conflict of Interest}

No conflict of interest.

\section{References}

1. Nyoman S, Sari RF (2013) Evaluating UI Green Metric as a tool to support green universities development: assessment of the year 2011 ranking. Journal of Cleaner Production 61(15): 46-53.

2. Greening Sustainability (2012) North Carolina Agricultural and Technical State University, USA. 